\title{
Réformes et prospective
}

Alain Bouvier et Marie-José Sanselme

\section{OpenEdition}

Journals

Édition électronique

URL : https://journals.openedition.org/ries/9267

DOI : $10.4000 /$ ries.9267

ISSN : 2261-4265

\section{Éditeur}

France Education international

\section{Édition imprimée}

Date de publication : 30 avril 2020

Pagination : 11-12

ISBN : 978-2-85420-626-5

ISSN : 1254-4590

Référence électronique

Alain Bouvier et Marie-José Sanselme, «Réformes et prospective », Revue internationale d'éducation de Sèvres [En ligne], 83 | avril 2020, mis en ligne le 30 avril 2020, consulté le 25 juin 2021. URL : http:// journals.openedition.org/ries/9267; DOI : https://doi.org/10.4000/ries.9267

(C) Tous droits réservés 


\section{Réformes et prospective}

La Revue internationale d'éducation de Sèvres a fêté en 2019 son vingtcinquième anniversaire. Avec 83 numéros publiés et plus de 1200 auteurs de 110 pays, cette revue internationale et comparatiste, publiée en français, est aussi, par son activité de traduction, une passerelle entre des aires linguistiques différentes. Nous l'animons, sous la houlette de son conseil scientifique présidé par le directeur général de France Éducation International, avec la collaboration du comité de rédaction et l'appui de l'établissement.

La revue est ainsi devenue, au fil du temps, une encyclopédie de l'éducation dans le monde, selon une formule de Mark Bray, que nous reprenons. Sa version papier est diffusée par les éditions Didier depuis 2002. Elle existe en outre au format numérique sur OpenEdition, où elle est la revue la plus consultée sur les questions d'éducation : près de deux millions de pages vues en 2019 , et ce chiffre augmente sans cesse. Son lectorat est étranger à $80 \%$. Enfin, la Revue internationale d'éducation de Sèvres est présente et bien placée dans la majorité des moteurs de recherche.

Ce $83^{\mathrm{e}}$ numéro est issu d'un colloque sur les conditions de réussite des réformes en éducation qui s'est tenu du 12 au 14 juin 2019 à Sèvres. Cette formidable aventure humaine et intellectuelle n'aurait pu être conduite sans le soutien des équipes de France Éducation International et de ses partenaires, que nous souhaitons ici remercier : en particulier le ministère de l'éducation nationale et de la jeunesse à travers sa délégation aux relations européennes et internationales et à la coopération, l'Organisation internationale de la francophonie, ainsi que les postes diplomatiques dans plusieurs pays, l'Institut des hautes études de l'éducation et de la formation, et les éditions Didier.

Des relations d'amitié et d'échange, parfois consensuelles, parfois contradictoires, ont été nouées entre experts, participants et intervenants venus de trente pays, et ce sont ces débats que nous proposons de prolonger avec ce numéro, "Réformer l'éducation ", qui a pour ambition, à notre demande, de proposer une lecture plurielle des évolutions qui se dessinent à l'horizon 2040.

Si, par tradition, la revue a toujours fait de la prospective à l'occasion de ses colloques internationaux et des numéros qui les prolongent $(40,52,68)$, cet exercice périlleux est encore plus affirmé dans ce numéro, en ces temps de mutations accélérées de nos sociétés, où il paraît plus que jamais nécessaire.

Ceci explique sans doute pourquoi tous les auteurs sollicités ont accepté de contribuer à ce numéro exceptionnel par son sujet, son volume et un sommaire inhabituels : ces experts internationaux livrent ici le fruit de leurs analyses et de leurs expériences, en veillant toujours à le contextualiser, depuis les plus sceptiques sur l'idée même de réforme aux plus enthousiastes.

C'est cet effort collectif de lecture du présent et, nous l'espérons, du futur, que nous livrons ici. 
À Jean-Marie De Ketele, qui coordonne ce numéro, nous voulons exprimer notre profonde gratitude et la joie que nous a donnée cette collaboration de tous les instants, pendant plus de deux ans.

C'est maintenant avec nos lecteurs que nous allons poursuivre cette réflexion.

\author{
Alain Bouvier, \\ Rédacteur en chef \\ Marie-José Sanselme \\ Rédactrice en chef adjointe
}

